\title{
Advance Stripper Configuration for Energy-Saving Designs Using Standard Monoethanolamine Absorbent for Post- Combustion Carbon Capture
}

\author{
Jiain LIU $^{1 *}$ and Ding-Sou CHEN ${ }^{2}$ \\ ${ }^{1}$ Department of Chemical and Materials Engineering, Tunghai University, Taichung, Taiwan \\ ${ }^{2}$ Green Energy and System Integration Research and Development Department, China Steel Corporation, Kaohsiung, Taiwan
}

\begin{abstract}
In a standard post-combustion carbon capture (PCC) process, the regeneration energy of the $\mathrm{CO}_{2}$ lean solvent dominates the overall energy consumption. The energy reduction achieved by stripper modifications, such as the cold-split bypass, interheated stripper, and integration of both configurations, have been reported in the literature. In the cold-split bypass, the cold rich stream is split to recover the energy contained in the overhead vapor that was directly fed into the condenser in the traditional stripper configuration. The interheated stripper draws the semi-rich solvent from the middle of the stripper and exchanges heat with the hightemperature lean solvent from the reboiler; thereby, the overall column temperature can be raised that favors $\mathrm{CO}_{2}$ desorption along the column. Therefore, the literature reported that the integrated modification, combining the cold-split bypass with the interheated stripper, takes both advantages of above modifications that can further reduce the energy requirement. However, the present work shows that energy-saving effect of integrated process is not as promising as the literature claimed. Once the feed stage of the warm-rich solvent is determined properly, the coldsplit process can achieve the similar energy-saving performance as that achieved by the integrated process.
\end{abstract}

\section{Introduction}

In an aqueous amine-based post-combustion carbon capture (PCC) process, the regeneration energy of the $\mathrm{CO}_{2}$ lean solvent dominates the overall energy consumption. The energy reduction in the stripper can be achieved by either formulating new solvents or optimizing the process configurations. Rochelle (2009) compared the economics of PCC on a 450-MW power plant in 2001 and 2006, and reported that the regeneration energy are 0.51 and 0.37 megawatt-hours per metric ton of $\mathrm{CO}_{2}\left(\mathrm{MWh} / \mathrm{t}-\mathrm{CO}_{2}\right)$, respectively, which are around 5.6 and $4.0 \mathrm{GJ} / \mathrm{t}-\mathrm{CO}_{2}$ estimated by $33 \%$ of thermal efficiency. The contributions of the energy reduction were due to the solvent improvement and better energy integration. However, the author declared that the solvent and process improvements are not additive for the energy reduction, the energy consumption less than $0.2 \mathrm{MWh} / \mathrm{t}-\mathrm{CO}_{2}\left(2.2 \mathrm{GJ} / \mathrm{t}-\mathrm{CO}_{2}\right)$ should not be expected.

Le Moullec et al. (2014) surveyed the process modifications for the energy saving of amine-based PCC technology from the patent databases and open literature, and categorized them into 20 elementary groups. They compared the energy reduction for each elementary group and reported that a reduction of $10 \%-12 \%$ in reboiler duty can be achieved by the cold-split bypass, and that the interheated stripper can reduce $13.4 \%$ of the energy consumption; however, according to their survey, the integration of both modifications can save $39 \%$ of the energy requirement. Lin et al. (2014) compared the energy-saving performance using $9 \mathrm{~m}$ (35 wt\%) MEA solvent. They reported that the reduction in reboiler duty is $5.9 \%, 8.0 \%$, and $10.6 \%$ for the cold-split bypass, interheated stripper, and integrated process, respectively. The results of the literature survey (Le Moullec et al., 2014) and simulation study (Lin et al., 2014) showed that the energy reduction by the cold-split bypass can be further driven by integrating it with inter-heaters (IHs). In the present work, the energy-saving effect of the advanced stripper configurations is investigated by the Aspen Plus V10.

\section{Simulation Model}

In this study, the Redlich-Kwong equation of state and the electrolyte-NRTL method were used to compute the properties of the vapor and liquid phases, respectively. The rate constants for the rate-controlled reactions can be found in the technical document (AspenTech, 2017). It should be noted that the two sets of rate constants for the $\mathrm{CO}_{2}$ desorbed from the carbamate of MEA are provided by AspenTech (2017). One is approximated by the reaction temperature from 30 to $80^{\circ} \mathrm{C}$, which is the range of absorber operation; and the other one is for simulating the stripper where the temperature is from 80 to $120^{\circ} \mathrm{C}$. The details of the parameter settings for the

\footnotetext{
*orresponding author: jialin@thu.edu.tw
} 
rate-based model can be found in AspenTech (2017). The simulation model was validated by the experiment data of Notz et al (2012), as shown in Figure 1. Since the $\mathrm{CO}_{2}$ absorption is diffusion-controlled reactions, the absorber was simulated by the rate-based model. Figure 1(a) shows the errors between the simulation results and the experiment data for the $\mathrm{CO}_{2}$ removal are within $\pm 10 \%$ that indicates the simulation model can describe the behavior of $\mathrm{CO}_{2}$ absorption by the MEA solvent. However, due to the high temperature in the stripper, the $\mathrm{CO}_{2}$ desorbed from the carbamate and bicarbonate may not be limited by the diffusion rate. Figure 1(b) compares the simulation results of stripper using the rate-base and equilibrium models with the experiment data of regeneration energy (Notz et al, 2012) where the errors are within $\pm 10 \%$ for the cases that the energy consumption are between 3.5 and $6.0 \mathrm{GJ} / \mathrm{t}-\mathrm{CO}_{2}$. Since the rate-based and equilibrium models have the comparable capability to describe the stripper behavior in the reasonable range of energy consumption, the equilibrium model was used to simulate the stripper in this study due to its simplicity on numerical convergence.

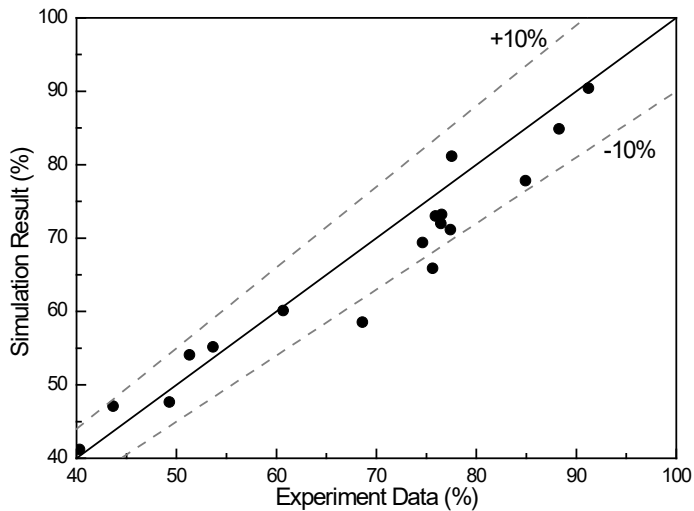

(a)

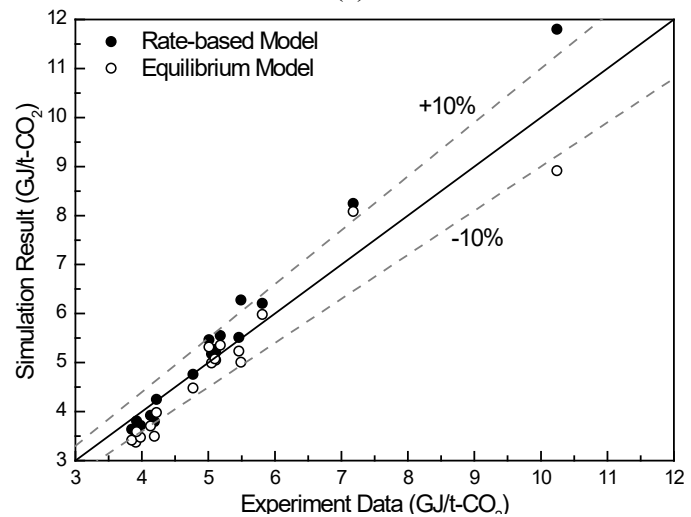

(b)

Figure 1. Verify the simulation model, (a) $\mathrm{CO}_{2}$ removal rate and (b) regeneration energy

\section{Standard Process}

In this study, the standard $30 \mathrm{wt} \%$ aqueous MEA solvent was used to capture $90 \% \mathrm{CO}_{2}$ from the flue gas of an exemplary $550 \mathrm{MW}$ coal-fired power plant (Ahn et al., 2013). The mass flow rate of the flue gas is $2067 \mathrm{ton} / \mathrm{h}$ at $43.6^{\circ} \mathrm{C}$ and $1.3 \mathrm{~atm}$; in addition, the gas composition is $4.06 \% \mathrm{H}_{2} \mathrm{O}, 2.20 \% \mathrm{O}_{2}, 78.09 \% \mathrm{~N}_{2}$, and $15.65 \% \mathrm{CO}_{2}$ by volume. Figure 2 shows a conventional amine-based PCC process configuration. The flue gas was fed into the bottom of the absorber where the cold lean solvent was trimmed to $45^{\circ} \mathrm{C}$ (Ahn et al., 2013) and fed into the column from the top to capture $90 \%$ of the $\mathrm{CO}_{2}$. The $\mathrm{CO}_{2}$ rich solvent was used to recover the sensible heat of the hot lean solvent by the cross-flow heat exchanger (HX) in which the rich solvent was preheated. Then, the warm rich solvent was fed into the stripper from the top and the overhead vapor was condensed at $40^{\circ} \mathrm{C}$. Ahn et al. (2013) reported that the estimated energy consumption in the stripper is around $3.5 \mathrm{GJ} / \mathrm{t}-\mathrm{CO}_{2}$ where the stripper pressure was operated at $1.9 \mathrm{~atm}$ and the lean loading 0.23 was applied; in addition, the absorber was packed with Flexipac 250Y. However, the column sizes were not reported in the work of Ahn et al. (2013). In this study, the column diameter was determined by $80 \%$ of the maximum flood capacity and the packed height was estimated by the rich solvent loading 0.49 (Ahn et al., 2013). The determined column diameter and packed height were 18 and $15 \mathrm{~m}$, respectively.

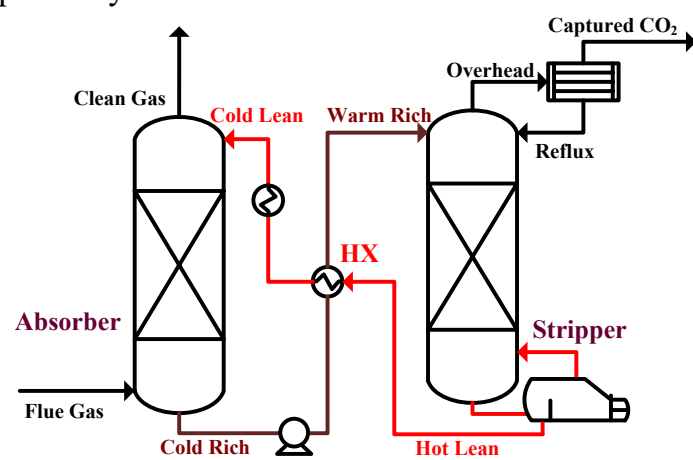

Figure 2. Process flow diagram of amine-based PCC

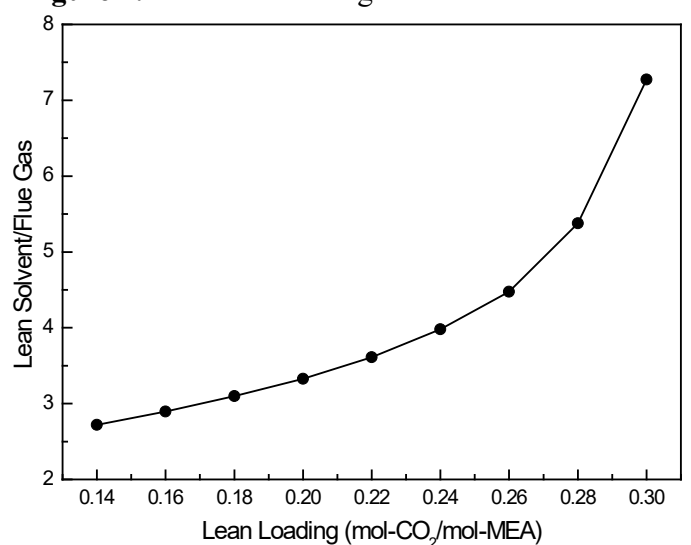

Figure 3. The ratio of required lean solvent to the flue gas

On the target of $90 \% \mathrm{CO}_{2}$ removal rate, the lean solvent requirement was proportional to the $\mathrm{CO}_{2}$ loading, as shown in Figure 3. Figure 4(a) illustrates the regeneration energy was proportional to the required lean solvent, in which 20 equilibrium stages were applied to simulate the stripper. In addition, as shown in Figure 4(a), the regeneration energy is around $3.6 \mathrm{GJ} / \mathrm{t}$ $\mathrm{CO}_{2}$ at lean loading 0.23 and pressure $2 \mathrm{~atm}$ that is close to the result of Ahn et al. (2013). Figure 4(a) also shows that the energy consumption can be relieved, as the stripper pressure increasing. Since the $\mathrm{CO}_{2}$ desorption is an endothermic reaction, high temperature in the column encourages the $\mathrm{CO}_{2}$ desorbed from the solvent. However, the thermal degradation of MEA solvent is accelerated when the reboiler temperature is above $135^{\circ} \mathrm{C}$ (Davis 
and Rochelle, 2009). Therefore, the advanced stripper configurations were investigated under the conditions of pressure at $3 \mathrm{~atm}$ and lean loading above 0.2 due to the temperature limitation, as shown in Figure 4(b).

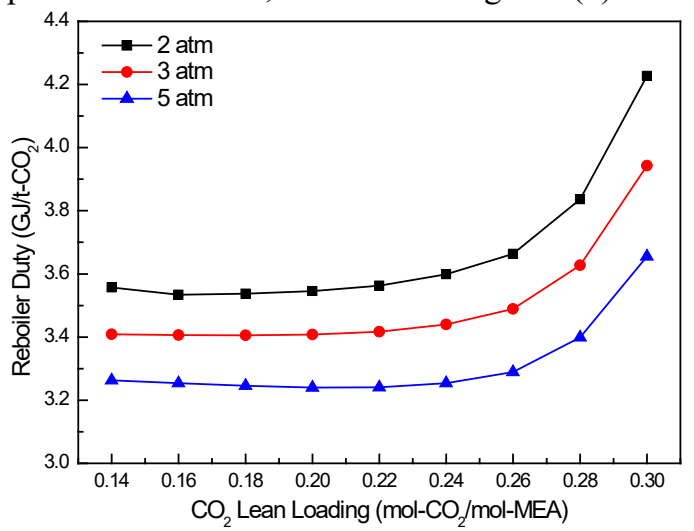

(a)

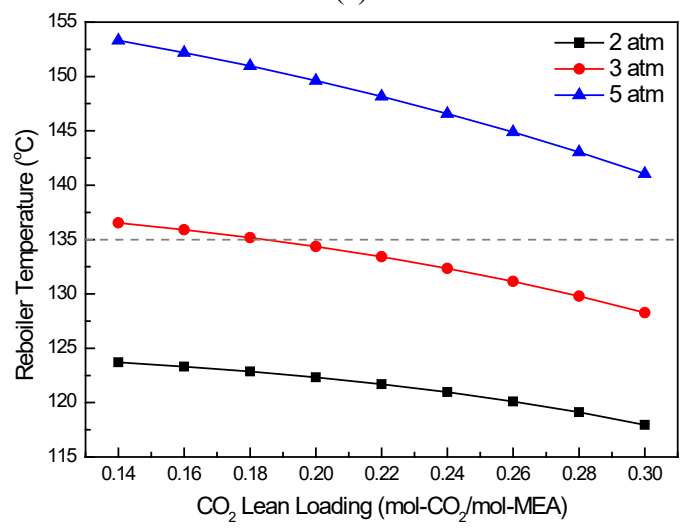

(b)

Figure 4. Regeneration of the lean solvent, (a) reboiler duty and (b) reboiler temperature

\section{Advanced Stripper Configurations}

\subsection{Cold-split bypass}

Figure 5 shows the process flow diagram of the coldsplit bypass, where a fraction of the cold-rich solvent was split and fed into the top of the $\mathrm{CO}_{2}$ stripper and the remaining cold-rich solvent was used to recover the sensible heat of the hot lean solvent and the warm-rich solvent that was fed into the stripper at a lower location than that of the cold-rich solvent. The feed stage of warm-rich solvent may affect the energy consumption for the cold-split bypass process. Figure 6 shows the results of varying the warm-rich feed stage and the coldsplit fraction at lean loading 0.22. As shown in Figure 6(a), when the feed stage of warm-rich solvent was maintained at the top, the reboiler duty was increasing as the cold-split fraction increasing where the dash line represents the energy requirement of traditional stripper. Since the more cold-rich solvent was bypassed and directly fed into the top of stripper, the top temperature was lower and the more sensible heat was needed.

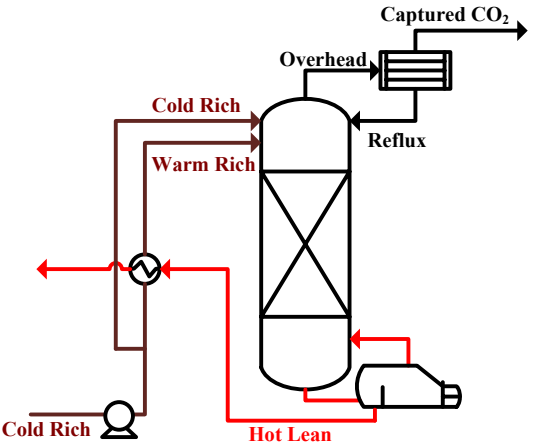

Figure 5. The flow diagram of the cold-split bypass

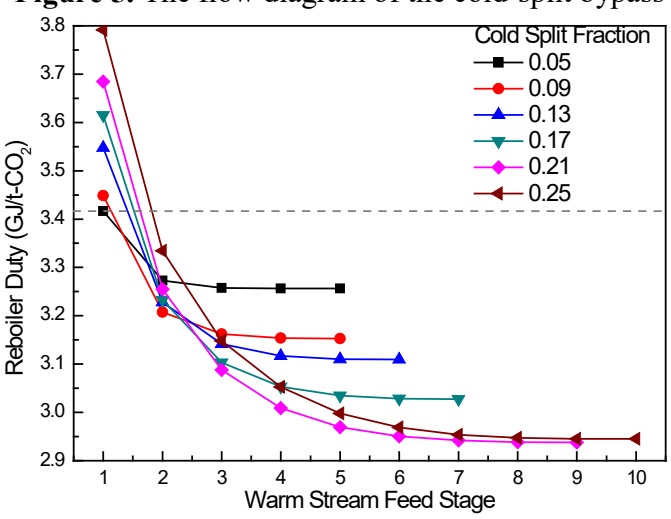

(a)

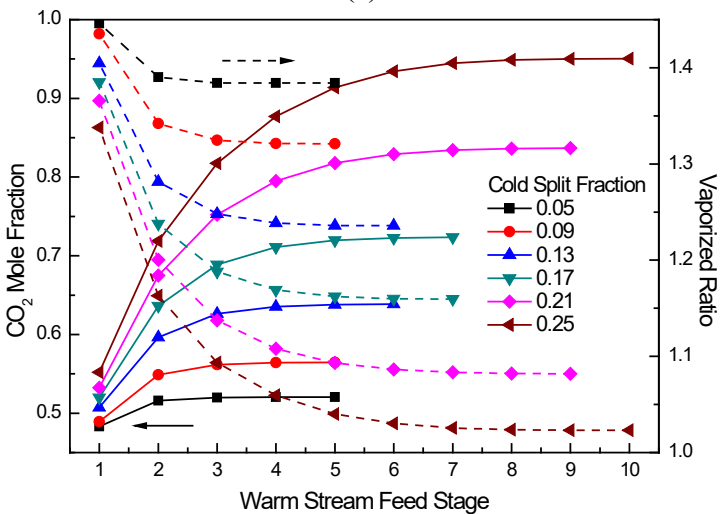

(b)

Figure 6. At $\mathrm{CO}_{2}$ lean loading 0.22 , (a) reboiler duty, (b) $\mathrm{CO}_{2}$ mole fraction (solid lines) and vaporized ratio (dash lines)

On the other hand, as the warm-rich feed stage was moving downward, the required energy was reducing to a constant value for the fix cold-split fraction. In addition, Figure 6(a) shows that the required energy was decreasing as the cold-split fraction increasing until the minimum of required energy at cold-split fraction 0.21 ; then, the required energy was increasing at cold-split fraction 0.25 . At a cold-split fraction, the top temperature of stripper was lowering as the warm-rich feed stage moving downward until the warm flow could not affect the top temperature; therefore, the $\mathrm{CO}_{2}$ purity on the top, which is the overhead flow in Figure 5, was increasing due to the lowering temperature, as the solid lines shown in Figure 6(b). For a constant $\mathrm{CO}_{2}$ removal rate, the higher $\mathrm{CO}_{2}$ purity in the overhead flow that leads to the less amount of vapor needs to be vaporized. Figure 6(b) compares the vaporized ratio of overhead vapor to the captured $\mathrm{CO}_{2}$ in which the high $\mathrm{CO}_{2}$ purity on the top resulting in the low vaporized ratio was 
demonstrated, as the dash lines show. Figures 6(a) and 6(b) suggest that the less amount of vapor provided by the reboiler duty may be the major energy-saving effect for the cold-split bypass.

The lowering top temperature of stripper favors the high purity of $\mathrm{CO}_{2}$ on the top that decreases the latent heat provided by the reboiler; on the other hand, that increases the required sensible heat of the stripper. Figure 7 shows the results of varying the $\mathrm{CO}_{2}$ lean loading and cold split fraction. At a fix lean loading (e.g., 0.22 ), Figure 7(a) shows that the vaporized ratio (solid line) was decreasing and the temperature difference between the top and bottom (dash line) was increasing, as increasing the cold split fraction. The required energy was reflected by the result of the competition between the latent and sensible heat, as shown in Figure 7(b). The figure also shows that the minimum required energy is around $2.91 \mathrm{GJ} / \mathrm{t}-\mathrm{CO}_{2}$ at lean loading 0.24 and cold split fraction 0.21 .

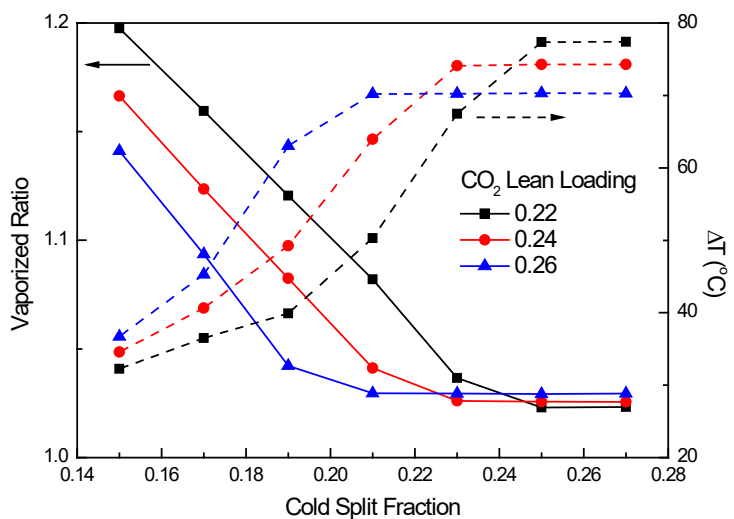

(a)

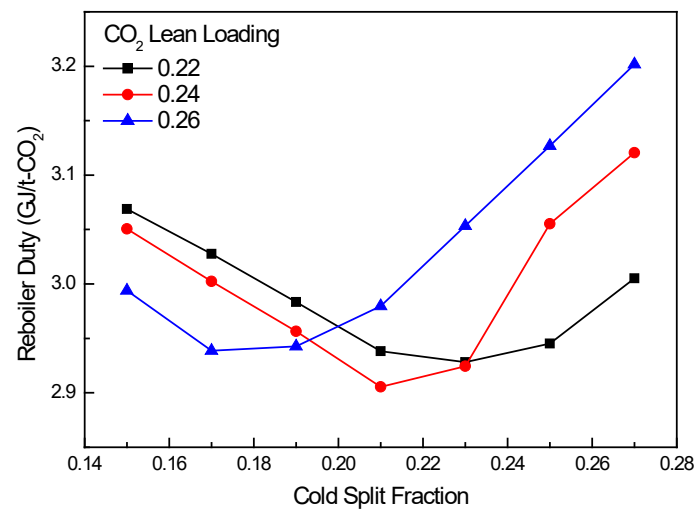

(b)

Figure 7. (a) vaporized ratio (solid lines) and the temperature difference (dash lines), (b) reboiler duty

\subsection{Cold-split bypass and interheated stripper}

In this study, the case of a single IH was considered. The semi-rich solvent was drawn from the tenth plate of the stripper and heated by the IH using the hot lean solvent, and the heated solvent was returned to the eleventh plate. Figure 8(a) compares the reboiler duty of standard and IH processes, in which the required energy consumption was reduced as the top temperature decreasing. Figure 8(b) illustrates that the $\mathrm{CO}_{2}$ purity in the overhead vapor was varying as the changes of the top temperature, whereas the vaporized ratio of the overhead flow to the captured $\mathrm{CO}_{2}$ was affected. Since the part of sensible heat of the hot lean solvent was recovered by the $\mathrm{IH}$, the temperature of warm-rich solvent was lower than that of the standard stripper. The results of Figure 8 demonstrate that the energy-saving explanation of the interheated stripper is identical to that of the cold-split process.

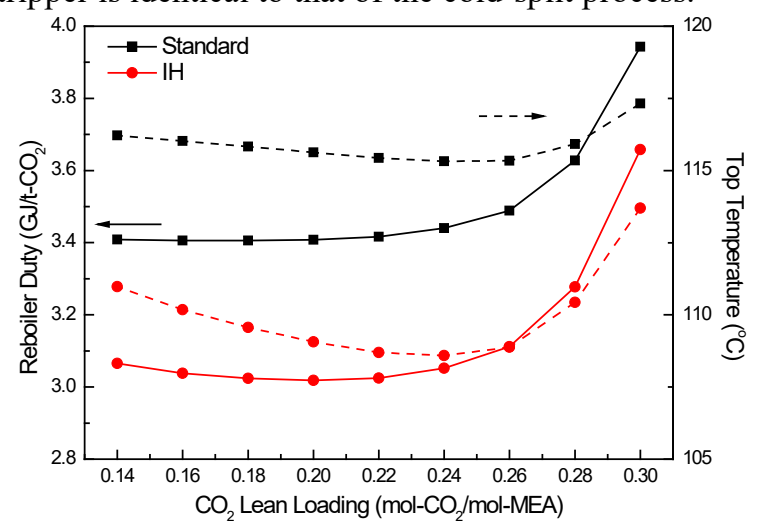

(a)

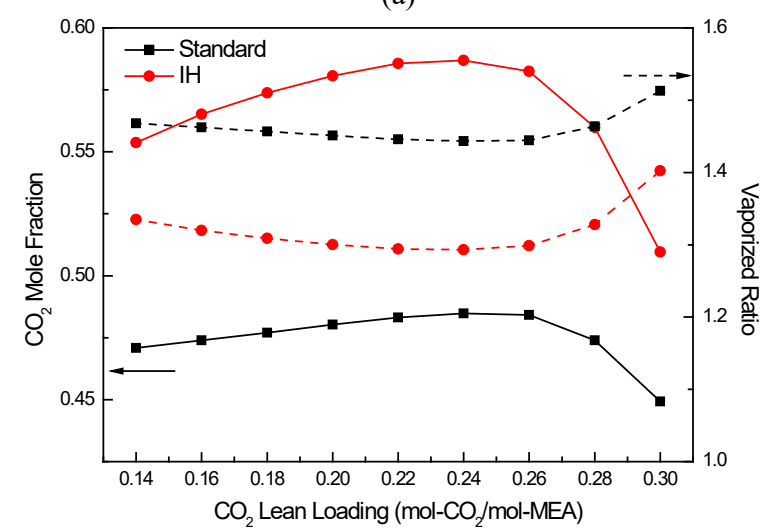

(b)

Figure 8. Comparison of the results of standard and $\mathrm{IH}$ processes, (a) reboiler duty (solid lines) and top temperature (dash lines), (b) $\mathrm{CO}_{2}$ purity (solid lines) and vaporized ratio (dash lines)

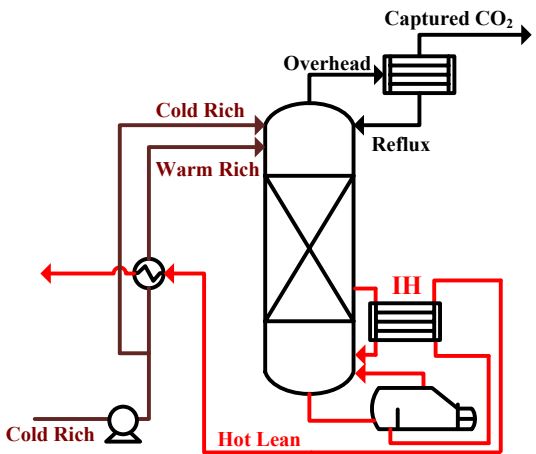

Figure 9. The flow diagram of the integrated process

Figure 9 shows the flow diagram for the cold-split process integrated with an $\mathrm{IH}$ in which the semi-rich solvent was drawn from the tenth plate, heated and returned to the eleventh plate. The feed location of warm-rich solvent was moved downward from the top until the reboiler duty was unchanged for a fix cold-split fraction. Figure 10(a) shows the required energy at lean loading 0.20 , as the warm-rich feed stage moving downward, in which the dash line represents the simulation result without cold-split flow. As the figure shown, at a fix cold-split fraction, the reboiler duty was reducing as the warm-rich feed stage moving downward until the warm stream cannot affect the energy 
consumption. As discussed earlier, the top temperature of the stripper was lowering as the warm-rich feed stage moving downward. The $\mathrm{CO}_{2}$ purity was increasing due to the lowering top temperature; therefore, the vaporized ratio of the overhead vapor to the captured $\mathrm{CO}_{2}$ was decreasing, as shown in Figure 10(b). The results of Figures 10(a) and 10(b) show that the energy reduction for the integrated process was also contributed by the less latent heat requirement.

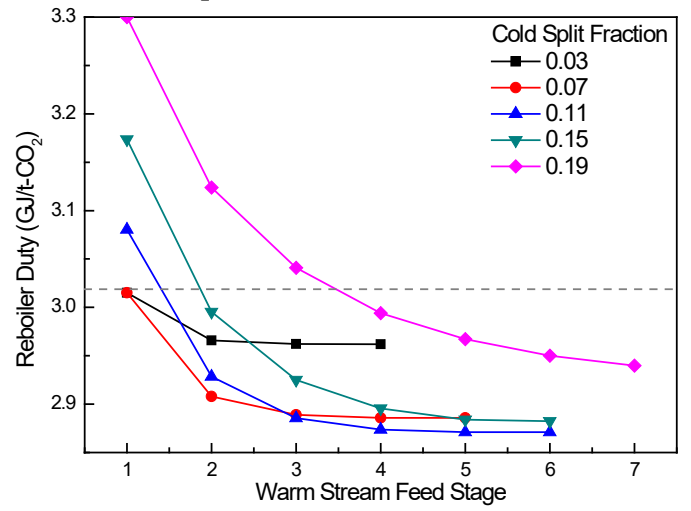

(a)

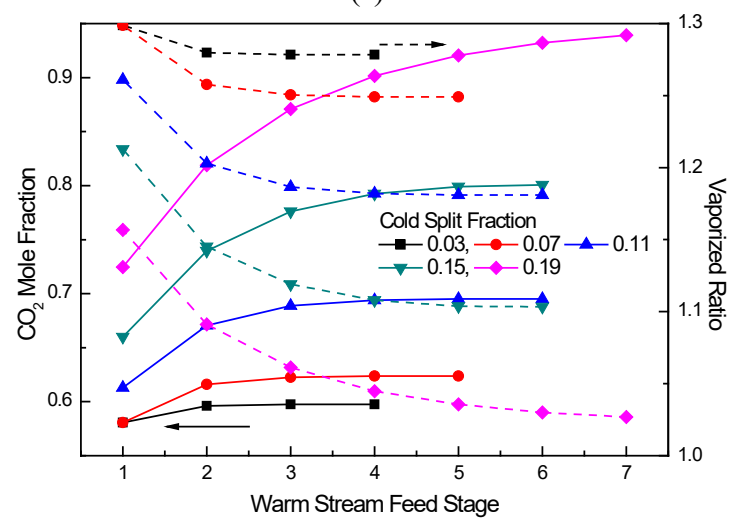

(b)

Figure 10. At $\mathrm{CO}_{2}$ lean loading 0.20 , (a) reboiler duty, (b) $\mathrm{CO}_{2}$ mole fraction (solid lines) and vaporized ratio (dash lines)

The low temperature at the top reduces the required latent heat for the reboiler at the cost of that the more sensible is needed. Figure 11(a) shows the decreases of vaporized ratio to the captured $\mathrm{CO}_{2}$ (solid lines) and the increases of temperature deference between the top and bottom (dash lines), as the cold-split fraction increasing. The competition results of latent and sensible heat are shown in Figure 11(b) where the minimum energy consumption $2.83 \mathrm{GJ} / \mathrm{t}-\mathrm{CO}_{2}$ can be found at lean loading 0.22 and cold-split fraction 0.11 .

\subsection{Summary}

In this study, the energy-saving explanation for the advanced $\mathrm{CO}_{2}$ strippers was investigated. In the review paper, Le Moullec et al. (2014) indicated the energy saving of the cold-split bypass was due to the heat recovery from the vapor that was directly passed into the condenser. The released vapor can be used to provide stripping heat for the cold-split solvent. However, in other aspects, the cold-split flow reduces the top temperature of the stripper that favors the higher purity of $\mathrm{CO}_{2}$ at the top; in the case of capturing the same amount of $\mathrm{CO}_{2}$, the less solvent needs to be vaporized by the reboiler, consequently. Figure 12 shows the correlation between the $\mathrm{CO}_{2}$ purity and the top temperature in which the larger symbols represent the minima of the required energy for the standard and advanced strippers listed in Table 1, and the data points were drawn from the simulation results of Figures 4, 7, 8 , and 11 . Figure 12 shows that the top temperature and the $\mathrm{CO}_{2}$ purity were increasing as the pressure increasing for the standard stripper, and the temperature difference between the top and the bottom was comparable, as listed in Table 1. The required energy for the standard stripper was reduced from 3.53 (2 atm) to 3.41 (3 atm) $\mathrm{GJ} / \mathrm{t}-\mathrm{CO}_{2}$, because the vaporization ratio was decreasing from 1.519 to 1.451 that was contributed by the $\mathrm{CO}_{2}$ purity at the top, which was increasing from 0.444 to 0.480 . As the stripper pressure increasing, the energysaving effect for the standard process was due to the high temperature in the column that encourages the $\mathrm{CO}_{2}$ desorbed from the solvent.

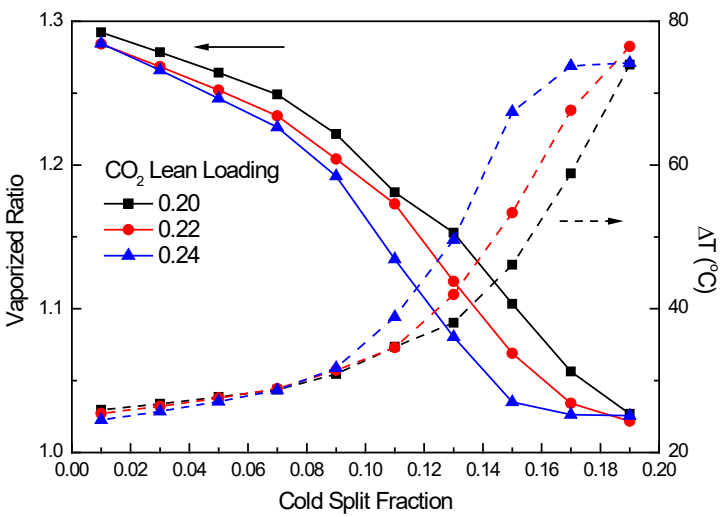

(a)

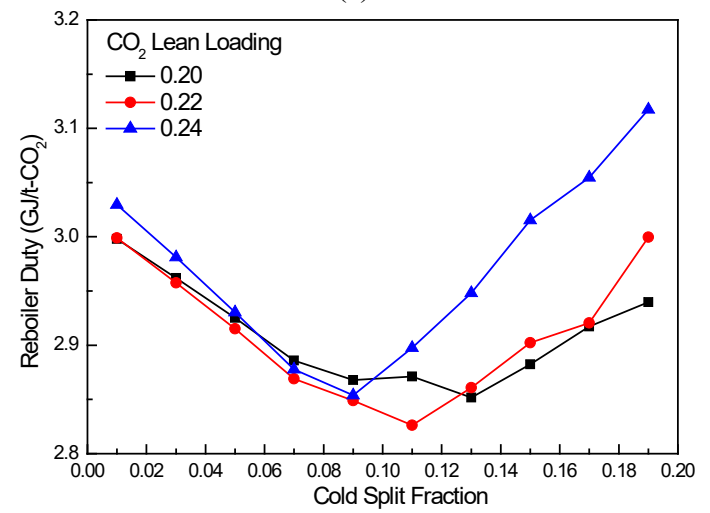

(b)

Figure 11. (a) vaporized ratio (solid lines) and the temperature difference (dash lines), (b) reboiler duty

On the other hand, once the stripper pressure was fixed, the $\mathrm{CO}_{2}$ mole fraction on the top can be increasing by reducing the top temperature. As shown in Figure 12, the common objective of the three advanced strippers was to reduce the top temperature where the stripper pressure was fixed at $3 \mathrm{~atm}$. The figure indicates that the interheated stripper was not an efficient way to reduce the top temperature. Table 1 compares the top temperature of the standard and advanced strippers where the temperature was reduced from 116 to $109^{\circ} \mathrm{C}$ by an $\mathrm{IH}$, and the top temperatures of cold-split and 
integrated processes can be reduced to 68 and $99^{\circ} \mathrm{C}$, respectively; therefore, the top purity of $\mathrm{CO}_{2}$ can be increased to $0.581,0.912$ and 0.704 , and the vaporized ratio of the overhead stream to the captured $\mathrm{CO}_{2}$ were $1.300,1.041$ and 1.173. However, the temperature differences of the three advanced strippers were 25, 64 and $34{ }^{\circ} \mathrm{C}$. The reboiler energy was the balanced result of the latent and sensible heat; as listed in Table 1, the energy consumption were $3.02,2.91$ and $2.83 \mathrm{GJ} / \mathrm{t}-\mathrm{CO}_{2}$, in which the energy saving respectively were $11.4 \%$, $14.7 \%$ and $17.0 \%$ comparing to that of the standard stripper at $3 \mathrm{~atm}$. The results show that the required energy of cold-split bypass can be further driven to a lower value by implementing an $\mathrm{IH}$; however, in this case, the extra $\mathrm{IH}$ only improved $2.3 \%$ of energy reduction that is not as promising as the literature claimed (Le Moullec et al., 2014; Lin et al., 2014).

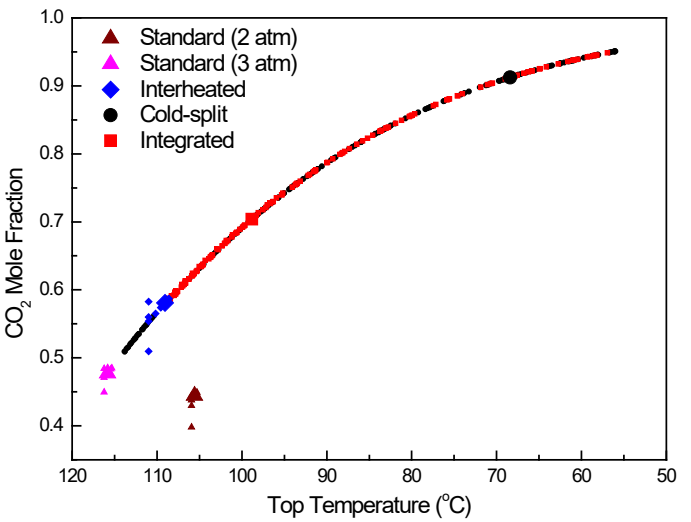

Figure 12. Correlation between the top temperature and the $\mathrm{CO}_{2}$ purity for the standard and advanced stripper configurations

Table 1. Summary of simulation results for the standard and advanced stripper configurations

\begin{tabular}{cccccc}
\hline & \multicolumn{2}{c}{ Standard } & Interheated & Cold-Split & Integrated \\
\hline $\mathrm{CO}_{2}$ stripper pressure $(\mathrm{atm})$ & 2 & 3 & 3 & 3 & 3 \\
Bottom temperature $\left({ }^{\circ} \mathrm{C}\right)$ & 123 & 134 & 134 & 132 & 133 \\
Top temperature $\left({ }^{\circ} \mathrm{C}\right)$ & 106 & 116 & 109 & 68 & 99 \\
$\square \Delta \mathrm{T}\left({ }^{\circ} \mathrm{C}\right)$ & 17 & 18 & 25 & 64 & 34 \\
$\mathrm{CO}_{2}$ mole fraction & 0.444 & 0.480 & 0.581 & 0.912 & 0.704 \\
Vaporized ratio & 1.519 & 1.451 & 1.300 & 1.041 & 1.173 \\
Cold-split fraction & & & & 0.21 & 0.11 \\
Warm-rich feed stage & & & & 9 & 6 \\
$\mathrm{CO}_{2}$ loading of lean solvent & 0.16 & 0.20 & 0.20 & 0.24 & 0.22 \\
$\mathrm{CO}_{2}$ loading of rich solvent & 0.50 & 0.50 & 0.50 & 0.49 & 0.49 \\
Lean solvent/flue gas & 2.89 & 3.33 & 3.33 & 3.98 & 3.61 \\
Reboiler energy $\left(\mathrm{GJ} / \mathrm{t}-\mathrm{CO}_{2}\right)$ & 3.53 & 3.41 & 3.02 & 2.91 & 2.83 \\
\hline
\end{tabular}

\section{Conclusion}

In a constant $\mathrm{CO}_{2}$ removal rate, the higher $\mathrm{CO}_{2}$ purity at the top of stripper, the less overhead vapor needed to be vaporized that was the common energy-saving explanation for the pressurized stripper and the advanced stripper configurations. Although the high temperature of pressurized stripper favored the $\mathrm{CO}_{2}$ desorption, the thermal degradation of the MEA solvent was accelerating when the reboiler temperature was above $135^{\circ} \mathrm{C}$. On the other hand, reducing the top temperature of stripper was the common effect of the advanced stripper configurations. The extra sensible heat due to the lowering top temperature competed with the saving latent heat; therefore, the determination of suitable top temperature was the crucial factor of energy saving for the advanced stripper configuration.

\section{Acknowledgements}

This work was supported by the Ministry of Science and Technology, Republic of China, under Grant 107-2221-E-029023 .

\section{References}

Rochelle, G.; "Amine Scrubbing for $\mathrm{CO}_{2}$ Capture," Science, 325, 1652-1654 (2009)
Le Moullec, Y., T. Neveux, A. A. Azki, A. Chikukwa, and K. A. Hoff; "Process Modifications for Solventbased Post-combustion $\mathrm{CO}_{2}$ Capture," Int. J. GreenH. Gas Con., 31, 96-112 (2014)

Lin, Y. J., T. Madan, and G. Rochelle; "Regeneration with Rich Bypass of Aqueous Piperazine and Monoethanolamine for $\mathrm{CO}_{2}$ Capture," Ind. Eng. Chem. Res., 53, 4067-4074 (2014)

Aspen Technology; Rate-based Model of the $\mathrm{CO}_{2}$ Capture Process by MEA Using Aspen Plus (2017)

Notz, R., H. P. Mangalapally, and H. Hasse; "Post Combustion $\mathrm{CO}_{2}$ Capture by Reactive Absorption: Pilot Plant Description and Results of Systematic Studies with MEA," Int. J. GreenH. Gas Con., 6, 84-112 (2012)

Ahn, H., M. Luberti, Z. Liu, and S. Brandani; "Process Configuration Studies of the Amine Capture Process for Coal-fired Power Plants," Int. J. GreenH. Gas Con., 16, 29-40 (2013)

Davis, J. and G. Rochelle; "Thermal Degradation of Monoethanolamine at Stripper Conditions," Energy Procedia, 1, 327-333 (2009) 